\title{
Insubordinación o golpe \\ Ecuador: la trama del 30-S, \\ de Juan J. Paz y Miño Cepeda
}

Víctor Hugo Torres Dávila*

El 30 de septiembre de 2010, el Ecuador vivió una insurrección policial, al mismo tiempo, una intentona de golpe de Estado, secuestro y tentativa de magnicidio del presidente Rafael Correa, acontecimiento que corre el riesgo de desaparecer de la historia si la 'justicia' absuelve a los implicados y se burla del pueblo ecuatoriano que salió a defender la democracia. "Entonces diremos: aquí no ha pasado nada. Y los testimonios y evidencias recogidas no serán más que simples sueños", concluye el historiador Juan Paz y Miño Cepeda en su libro de reciente publicación en el que analiza las condiciones y actores, individuales y colectivos, con sus intereses y pasiones, que se movilizaron en torno a tales acontecimientos.

La obra de Paz y Miño es uno de los pocos estudios académicos, seriamente documentado, que explica los hechos del denominado "30-S", recurriendo a los testimonios de los principales actores y a una profusa documentación basada en fuentes testimoniales y sobre todo informáticas, grabaciones y videos. Aunque cabe esperar que aparezcan nuevos trabajos, hay que admitir que es un esfuerzo, en solitario, pues la mayoría de académicos ecuatorianos están alineados en la oposición al gobierno de Rafael Correa, sobre todo porque no admiten que sus teorías y enfoques liberales, individuales y comunitarios, no encajen en la explicación de los procesos políticos, gubernamentales y públicos que está viviendo el país, todavía insisten en que la realidad se someta a la teoría. De ahí que acerca del 30-S, predominen las opiniones y no los análisis empíricamente sustentados, lo que paradójicamente, aunque no se lo proponga, también contribuye a robustecer la imagen de que lo que aconteció puede quedar en "un simple sueño".

El libro efectivamente cumple el doble propósito de su autor: registrar los eventos para que no se pierdan con el tiempo, y darles significado en el presente. Su formulación alineada en la campo de la Historia Inmediata o historia del presente, permite captar la complejidad de los eventos suscitados, de manera extraordinaria, en un solo día, cuando se puso en peligro a la democracia y en

Profesor de la Universidad Politécnica Salesiana del Ecuador 
riesgo al gobierno, al tiempo que despertaron los temores latinoamericanos ante el golpismo. Al decir de Paz y Miño, el país experimentó en un mismo día un proceso histórico, pues se trató de un día-proceso con distintas fases.

En efecto, empezó temprano en la mañana, con una condensación de la inconformidad del personal policial ante las reformas institucionales que eran vistas como políticas anti-policiales. A media mañana, se dio paso a una insubordinación policial centrada en Quito y coordinada en todo el país, la que siendo inconstitucional e ilegal concitó el apoyo de los partidos políticos opositores, algunos dirigentes indígenas y ciertos medios de comunicación. Como consecuencia, el Presidente quedó atrapado en un hospital policial y el Ejecutivo bloqueado, el Vicepresidente varado en Guayaquil, los Ministros de Estado desconectados, los gobernadores fuera de sus provincias, el Legislativo sitiado e impedido de reunirse, la Función Judicial obstaculizada y las Fuerzas Armadas en alerta.

Durante la tarde, se confabularon los sectores de la oposición política pidiendo la salida del Presidente. Se trató de una conspiración desorganizada e improvisada, en la que se entrecruzaban los pedidos de revocatoria del mandato, amnistía para los comprometidos con la revuelta, disolución de la Asamblea para ir a la 'muerte cruzada', llamadas a un 'frente de resistencia nacional' y a la salida constitucional de Correa.

En la noche, se intentó asesinar al Presidente, desencadenándose un enfrentamiento militar policial que lo liberó. El día se cerró alrededor de las 23 horas con una cadena nacional en la que Rafael Correa ratificó que se trató de una "conspiración contra el régimen utilizando a la policía", con varias personas fallecidas, numerosas heridas y agraviadas, pero que puso a prueba la "lealtad de sus funcionarios y el respaldo popular".

En el libro queda claramente demostrado que fueron dos eventos distintos con cursos de acción entrecruzados: una insubordinación protagonizada por un sector policial "expresada como protesta", y un intento de golpe de Estado, protagonizado por actores individuales y grupales que canalizaron "intenciones y esperanzas escondidas" de que acabe el gobierno, o de que salga el presidente Rafael Correa.

Asimismo, se argumenta con claridad que luego de transcurridos los acontecimientos se buscó reducirlos a un "problema entre el Presidente y los poli- 
cías levantados", pues quienes intentaron aprovechar el descontento policial para sus afanes golpistas abandonaron la escena cuando el pueblo salió a defender la democracia, las Fuerzas Armadas respaldaron la constitucionalidad, la Asamblea Nacional no se reunió, y el apoyo internacional a Correa fue unánime y en contra de la desestabilización democrática.

De entre los múltiples aspectos analizados por Paz y Miño, interesa destacar brevemente el rol de las instituciones públicas de policía y justicia con el propósito de contribuir a la comprensión sobre el alcance de los acontecimientos del "30-S", pues junto con la intentona golpista que buscó desplazar del poder al Presidente, se evidenció lo que consideramos es uno de los límites del Estado-nación frente al proceso de cambio que desde el gobierno se está impulsando en el país.

Es el fenómeno de la burocracia restauradora denominado también "inercia burocrática" del aparato público, calificado desde el inicio por el propio Presidente, como el "principal enemigo interno". El que la policía haya sido el epicentro de la insurrección, y la justicia opere posteriormente como el mecanismo de expiación de la insubordinación y el golpismo, no fue fortuito ni accidental, sino que forma parte de un comportamiento de naturaleza estructural que permea al régimen político. Es una tendencia histórica -podría decirse- de que en los momentos de cambio, o de reforma vividos en el país, la burocracia estatal tiende a restaurar el orden del pasado, pues, o bien sintoniza conflictivamente $\mathrm{o}$ de plano resiste a las orientaciones públicas de cambio. No es solo un problema de agencia en la gestión de las políticas públicas, sino una tensa articulación de intereses público-privados que frenan las transformaciones sociales.

La policía nacional, al igual que muchas otras instituciones públicas, ha vivido un largo y tortuoso camino de institucionalización y profesionalización hasta que recientemente a comienzos de los años setenta del siglo XX, logró una estructura institucional definitiva, cuando el Estado impulsaba el desarrollo y la modernidad del país. Sin embargo, casi inmediatamente fue interceptada por las fuerzas e intereses que desmontaron la institucionalidad estatal y dispersaron la rectoría pública policial, configurando en las décadas siguientes una entidad desarticulada con unidades autónomas, mandos directos e independientes entre sí, con lealtades y jerarquías externas, cobijados por una escuela policial de violencia y corrupción tanto interna como hacia la sociedad. 
Cuando el gobierno de Correa emprendió los cambios para la recuperación y fortalecimiento institucional de la policía desde una perspectiva de los derechos ciudadanos, emergieron las fuerzas oscuras acostumbradas a la no institucionalidad policial y exacerbadas ante la nueva Ley de Servicio Público, quienes protagonizaron primero la insubordinación y luego coaligadas el golpe de Estado.

La institución de la justicia ha seguido un curso similar, acostumbrada desde los inicios de la República a ser parte constitutiva del aparato público, alcanzó a mediados del siglo XX una institucionalidad también sometida a las interferencias del poder político, paradójicamente, bajo el principio de mantener su independencia. La justicia en el país opera bajo los mismos códigos de desarticulación de autoridades, jueces, abogados y mecanismos jurídicos, configurando densas y complejas redes de clientela, influencias y corrupción que sigue los patrones del poder político: está concentrada en los mismos lugares, opera principalmente dentro de las ciudades y solo en determinadas zonas, carece de una visión territorial y no se ve a sí misma como un servicio público ciudadano. Como lo ha señalado Paz y Miño, la institucionalidad judicial quedó rezagada frente al avance de la sociedad y de las otras Funciones del Estado.

El hecho es que aunque determinados estamentos policiales y judiciales integren las mismas redes de corrupción y violencia, la policía y la justicia son parte de la burocracia estatal, como tales tienen un comportamiento tradicionalista que tiende a la restauración del orden, y que se expresó el "30-S" cuando la primera resistió a la transformación y se insubordinó ante la institucionalidad, mientras la segunda 'aplica justicia' y absuelve a los implicados.

¿Qué es la burocracia restauradora? Más allá de las disquisiciones acerca de los intereses propios de la burocracia como propia del Estado liberal moderno, aludimos a una tendencia histórica ecuatoriana tempranamente advertida por Maiguashca (2003), en la conformación de la república y luego en los gobiernos de la denominada 'república práctica', en los que se avanzó decisivamente hacia el Estado nacional, mientras la burocracia provista desde la sociedad estamental tendió, en contramarcha, a la restauración del orden colonial y plutocrático.

A mediados del siglo XX, durante los gobiernos civiles y militares modernizadores en los que desde el Estado se impulsó la expansión económica y 
social, la burocracia estatal nuevamente en comportamiento regresivo, tendió a la restauración del orden señorial, patricio y oligárquico anterior. En los albores del siglo XXI, con una Constitución innovadora que propone alcances desafiantes hacia el Estado plurinacional e intercultural, con un proceso sostenido de reforma estatal y de ampliación de la esfera pública, la burocracia otra vez en actitud regresiva tiende a la restitución del orden neoliberal precedente.

Durante las tres décadas anteriores, el Estado ecuatoriano fue sometido a una creciente desinstitucionalización que auspiciaba el manejo privado de la inversión pública, la fragmentación en múltiples entidades autónomas de su capacidad decisora y rectora, la entrega de la política pública a la sociedad corporativizada y al mercado, la privatización de algunas empresas estratégicas y la desinversión en el área social. En el país, la pérdida de la institucionalidad democrática está asociada más que con el populismo, con la adopción criolla del neoliberalismo.

Por ello, la insubordinación policial y el complot golpista del "30-S" tuvieron como base social a la burocracia restauradora, la que todavía mantiene ramificaciones sectoriales con intereses privados enraizados en el lado oscuro de lo público. Inclusive, otros estamentos burocráticos también quisieron, timoratamente, sumarse a la insubordinación y al golpe, pero la indecisión y el mal cálculo pudo más.

Los acontecimientos del "30-S" pusieron en evidencia un complejo problema de fondo para el proyecto de cambio gubernamental: la resistencia de la burocracia estatal a la reforma democrática del Estado, lo cual no se resuelve solo con recambios generacionales de funcionarios o reingenierías institucionales sobre funciones y competencias, necesarios sin duda pero insuficientes, pues tanto las nuevas generaciones cuanto los diseños institucionales vienen también impregnados de valores y prácticas neoliberales.

Después del 30-S se hace necesario profundizar el proceso de cambio democrático, ampliando y fortaleciendo la esfera pública, renovando la institucionalidad estatal, para lo cual cabe configurar en el día a día una vía propia de renovación estatal que se distancie del comportamiento restaurador de la burocracia pública. Tal vez las fuerzas políticas de derecha no están muy entusiasmadas en los golpes de Estado, al menos 
explícitamente, porque la burocracia pública es suficiente para bloquear y retardar los cambios democráticos que requiere el país.

\section{Bibliografía}

Maiguashca, Juan. "Dirigentes políticos y burócratas: el Estado como institución en los países andinos, entre 1830 y 1880", en Juan Miguashca (Editor), Historia de América Andina, Volumen 5, Creación de las Repúblicas y Formación de la Nación, Universidad Andina Simón Bolívar, Ecuador: Libresa, 2003. 